\title{
LA ENSEÑANZA DESDE LAS IDEAS MICHEL FOUCAULT
}

\author{
Janine Peñaloza Guerrero ${ }^{1}$ \\ UPEL, Venezuela \\ Recibido: 5/2/2015 \\ Aceptado: 14/4/2015
}

\begin{abstract}
Resumen:
La enseñanza es una actividad humana en la que unas personas ejercen influencias sobre otras. Estas influencias se practican, como parte de la relación de desigualdad de poder y autoridad entre el docente y el estudiante. Esta ponencia analiza el contexto educativo universitario venezolano. La investigación se trabajó haciendo uso de la Metodología Cualitativa, Paradigma Interpretativo, la información se recolectó a través de: fuente documental, observación y entrevista, se analizaron los resultados mediante la Teoría Fundamentada de Strauss y Corbin y el proceso de teorización de Martínez, a través de comparaciones entre el proceso histórico de la didáctica, las ideas de Foucault y aspectos de la práctica educativa actual. Entre las consideraciones finales se tiene que es necesario desarrollar una didáctica que apueste más por la libertad de los actores del proceso educativo y menos por la represión, el control y la vigilancia.
\end{abstract}

Palabras clave: Docente, Estudiante, Poder.

\begin{abstract}
:
Teaching is a human activity in which people exercise some influence over others. These influences are practiced as part of the relationship of unequal power and authority between teacher and student. Is paper analyzes the Venezuelan university educational context. The research work was done using Qualitative Methodology, Interpretive Paradigm, information was collected by: documentary source, observation and interview results by Grounded Theory of Strauss and Corbin and the process of theorizing Martinez were analyzed to through comparisons between the historical process of teaching, the ideas of Foucault and aspects of current educational practice. Among the final considerations is the need to develop a teaching that bet more freedom of education stakeholders and less by repression, control and surveillance.
\end{abstract}

Keywords: Teacher, Student, Power.

${ }^{1}$ janinecpg@gmail.com 


\section{Introducción}

La presente investigación parte de una motivación que obedece a las vivencias propias del quehacer educativo, lo que genera un cuestionamiento de los procesos que conducen a la formación del estudiante desde una mirada normalizadora del docente. Debido a esto se estudia la práctica educativa universitaria, la cual encierra actividades intelectuales orientadas a la construcción del conocimiento, empleando diversas estrategias y recursos para facilitar el aprendizaje de los estudiantes.

La práctica educativa universitaria gira en torno a las actividades intelectuales implicadas en la construcción del conocimiento, utilizando diversas estrategias y recursos a fin de facilitar el aprendizaje de los estudiantes. Proceso complejo al interactuar factores inherentes a la administración del acto pedagógico en las aulas universitarias. Por tanto, la enseñanza al ser una actividad humana, se da de manera tal que personas ejercen influencias sobre otras. Estas influencias se practican, como parte de la relación de desigualdad de poder y autoridad entre el docente y el estudiante.

Se concibe la práctica educativa como un proceso complejo por tal razón la ponencia, está enfocada en la práctica educativa y en el poder; considerándose especialmente la relación docente-estudiante y utilizando los postulados de Michel Foucault, como luz y guía, en la elaboración de lineamientos de la práctica universitaria y relacionarla con el poder, considerando especialmente la Obra Vigilar y Castigar. Sobre la base de esos planteamientos y analizando la propuesta de este autor, se establecerán comparaciones que coadyuvarán en reflexiones sobre el ámbito universitario, para el establecimiento de criterios novedosos que permitan mejoras y aportes significativos a los paradigmas existentes.

\section{Objetivo General}

Concebir una estructura teórica sobre la Didáctica Universitaria a la luz de la obra Vigilar y Castigar de Michel Foucault.

\section{Objetivos Específicos}

1. Analizar la evolución histórica de la didáctica educativa con relación a los principios desarrollados por Michel Foucault. 
2. Interpretar la obra Vigilar y Castigar de Michel Foucault en relación a la didáctica educativa.

3. Construir una estructura teórica de la Enseñanza desde las ideas de Michel Foucault.

\section{Referentes Metodológicos}

Considerar los postulados de Michael Foucault en su obra Vigilar y Castigar como eje problematizador dentro de la práctica educativa universitaria, con vigencia claramente apreciable, es un inicio importante, mediante la cual se puede generar teoría a fin de adentrarse en el ámbito educativo universitario. Por tanto, la investigación es Cualitativa bajo el paradigma Interpretativo, y los resultados fueron analizados a través de la Teoría Fundamentada de Strauss y Corbin.

\section{Interpretación de los resultados obtenidos}

A la luz de Foucault se puede analizar, bajo un ambiente crítico, ideas que permitan entender al sujeto como un blanco de poder que está sometido a unos intereses propios de mecanismos de producción, determinados por prácticas de poder y saber, con miras a profundizar la práctica educativa universitaria, buscando acciones que mejoren el desarrollo del acto de enseñar.

En tal sentido, es importante romper con el modelo de "educación tradicional”, emergiendo así, con Foucault, un cuestionamiento radical de los procesos que conducen a la formación del sujeto desde una mirada normalizadora-represiva del docente, logrando articular esta situación al proceso educativo universitario, partiendo de allí generar una teoría orientada a una educación más humanizadoraLuego del estudio de la obra Vigilar y Castigar y del análisis de la información recolectada, surgió la necesidad de correlacionar la problemática existente en la forma de enseñar, con las ideas manifestadas por Foucault y otros autores afines a los objetivos e intereses perseguidos por la investigación.

En esta fase de contrastación puede llevar, a lo que señala Martínez (2006)“ ... hacia la reformulación, restructuración, ampliación o corrección de construcciones teóricas previas, logrando con ello un avance significativo en el área” (p.277). De tal manera, que lo que se presenta a continuación permitirá dar luces al procedimiento 
siguiente que corresponde a la teorización. Para ello, se hace mención a citas de autores que fueron trabajados en el marco referencial, todo con la finalidad de describir las categorías halladas en el desarrollo de la investigación y que tienen la mayor significación. En consecuencia, para ordenar la estructuración, se presenta en tres unidades generales definidas de la siguiente forma:

1. Concepciones de la Didáctica y su analogía con la obra de Foucault.

2. La Universidad como escenario de la investigación, y su influencia como institución disciplinaria.

3. El poder desde la óptica Foucaulteana y su influencia en la educación.

\section{La didáctica (docente, estudiante, discurso y espacio) y su analogía con la obra de Foucault Didáctica: Arte de Enseñar}

Se considera que la premisa que más se acerca a la didáctica es la del arte de enseñar, por el valor sensible que le aporta a la forma de como el docente debe actuar, es decir, como un artista que aspire plasmar todos sus conocimientos en sus estudiantes. Para ello es necesario ver al "arte”, desde su esencia, al respecto, Heidegger (2007) plantea en su obra el origen de la obra de arte: "la obra surge a partir y por medio de la actividad del artista... el artista es el origen de la obra. La obra es el origen del artista. Ninguno puede ser sin el otro”. (p.11).

Se destaca que el arte, dentro del acto educativo se da por medio de la creatividad e iniciativa del profesor conjuntamente con el estudiante y el medio circundante. Donde se dé la interacción: del medio, el docente, el estudiante y la comunidad. Desarrollando estrategias que contribuyan a la formación del ser integral que se busca en el estudiante, induciendo en él a un aprendizaje significativo. Puesto que el arte transporta, emerge en un interés especial, donde el profesor es el promotor principal del proceso de enseñanza-aprendizaje en una actividad transformadora, crítica y reflexiva, en conjunción con el estudiante y los distintos medios.

De la misma forma, como el artista mantiene una conexión que va más allá de una imagen o del reflejo de una cosa con su obra, las estrategias empleadas por los docentes deben tener un vínculo, un propósito, un interés que trascienda el deseo de sólo transmitir contenidos. Estrategias que permitan obtener intercambios significativos en el desarrollo del hecho educativo; y permita reflexionar sobre lo planteado por 
Foucault: ¿Para qué pintaría un pintor sino para ser transformado por su propio trabajo? (p.154).

En lo que se refiere a la didáctica universitaria, se requiere de un cambio, una transformación, debido a la obsolescencia, apatía e inercia con que, en la mayoría de los casos, se continúa ejerciendo la profesión de docente. El profesor no puede seguir siendo el único centro del proceso educativo; considerándose así mismo como la "única fuente” de saber y de conocimiento. El exceso de autoritarismo e imposición hace que se caiga en lugares comunes y en experiencias de la vida que dejan de lado el accionar del estudiante y sus vivencias.

Comenio estaba convencido que a cada hombre se le da la oportunidad, para desarrollar su capacidad creativa, para alcanzar la perfectibilidad continua e interminable, lograr la educación continua y permanente y para la autoeducación, todos tienen el deber de aprovechar al máximo las oportunidades presentadas

El hombre desde su nacimiento ha sido influenciado por personas que buscan promover en él una enseñanza, que posteriormente se convertirá en un aprendizaje y que le ayudará a formarse dentro de una sociedad. El ser humano busca esa formación dentro del sistema educativo mediando entre teoría y práctica para ubicarse dentro del plano macro, es decir, sentirse reconfortado de lograr sus metas u objetivos. Según Comenio:

La Naturaleza nos da las semillas de la Ciencia, honestidad y religión, pero no proporciona las mismas Ciencia, Religión y Virtud; éstas se adquieren rogando, aprendiendo y practicando. De aquí se deduce que no definió mal al hombre el que dijo que era un Animal disciplinable, pues verdaderamente no puede, en modo alguno, formarse el hombre sin someterle a disciplina. (p.15)

El hombre siempre está imbuido en relaciones de poder como producto de ser un agente social, el cual hace que esa influencia recibida desde su interior y por fuerzas externas deformen su acción dentro de la sociedad. Por tanto, debe doblegarse ante sistemas disciplinarios que permitan moldear su conducta, proporcionando una repetición en serie de patrones y modelos, que se desarrollan por inercia y no por criterios propios. De allí que resulta conveniente señalar que "el hombre ha sido llamado por los filósofos microcosmo, compendio del Universo, que encierra en sí 
cuanto por el mundo aparece esparcido” (ob. cit.) (p.10). El hombre ha sido comparado con una semilla, a la que se debe cuidar para que su germinación se consolide de manera positiva, productiva y virtuosa, y para lograrlo debe estar en tierra fértil, es decir, en un escenario propicio para desarrollar potencialidades que permitan su integralidad.

Por tanto, para que la educación esté en vía de lograr la liberación debe asumir lo que Señala Nietzsche (2000b):

Arranca la cizaña, retira los escombros, aleja el gusano que destruye los tiernos gérmenes de las plantas, irradia luz y calor, actúa con la benéfica llovizna nocturna, imita e implora a la naturaleza en lo que ésta tiene de maternal y compasiva. (p.136).

Se debe apartar todo aquello que entorpezca con la labor educativa, todo lo que cause daño, malestar, que enferme, que envicie. Se debe buscar la luz natural para hacer brillar y contemplar la plenitud de la obra.

En tal sentido, el hombre es el principal transformador, él que a través de sus experiencias y conocimientos adquiridos dará vida, luz, forma, arte a las cosas y objetos que surjan en el medio. Se puede considerar como el artista que toma un pincel y a través del lienzo pueda desplegar toda su creatividad, su invención, su ingenio y dejar volar su imaginación para la creación de obras que le permitan navegar en un mar profundo.

Concebida la Didáctica como el “arte de enseñar”. Como la disciplina encargada de guiar, orientar y facilitar la enseñanza en el proceso educativo, por medio de la subjetividad natural del docente y del estudiante, hacen que la enseñanza actúe como un ejercicio de compromiso, de ética, de respeto y de libertad.

Para Kerschensteiner la enseñanza es un acto de comprensión. Esto permite reflexionar que desde épocas anteriores se ha venido gestando movimientos que han buscado la inclusión y democratización del conocimiento, como elemento de preparación para la vida.

En el acto educativo, el docente como uno de los actores principales, tiene el deber de ser promotor, mediador y facilitador del proceso, así como también debe asumir la actitud de ser virtuoso. Esta actuación hace que su rol influya de forma significativa y profunda en el estudiante. Ejemplo: los niños siempre sienten una fuerte 
inclinación a identificarse con los héroes de historietas. En este caso, los estudiantes tienden a seguir al docente como su ejemplo y su modelo, llegando a convertir el proceso educativo, en un gran compromiso de responsabilidad por parte de quienes están al frente de esta profesión. Así como lo manifiesta otro de los grandes pedagogos que ha marcado huella en el discurrir histórico de la educación: Pestalozzi, quien resalta el amor por la vocación de educar. Quien educa debe tener una formación integral y conocimiento de su rol para que de esta manera pueda asumir responsabilidades y convertirse en el ejemplo y modelo a seguir.

En contraposición con lo expuesto anteriormente, se afirma que muchas veces el docente se mueve en un escenario donde goza del respeto, admiración y atención que lo puede desviar de su verdadero rol. Por lo que se puede considerar, que es un tabú y una ambivalencia arcaica ver al docente como la persona a la que se le atribuye facultades para alcanzar la formación integral de los estudiantes. Tal como ha sido observado en los ambientes de clase de la universidad y expresado por los estudiantes como una realidad, de las actividades académicas que a diario se viven. Muchos de los docentes hacen prácticas que contravienen los principios expresados por los representantes de la Escuela Nueva. Dice Rousseau: la pedagogía que apele a una vocación social debe ser, asimismo, una pedagogía de la libertad.

Persiste, sin embargo, más allá de toda duda, discrepancias entre el espíritu, el estatus y la influencia, que el docente tiene, al menos en el orden ideológico. Estas discrepancias no dejan de tener consecuencias en el espíritu, es decir, en la esencia del arte de enseñar. Para Dewey: el acto educativo no es un proceso de desenvolvimiento desde dentro, ni un adiestramiento de facultades que residen en el espíritu mismo. Es más bien la formación del espíritu por el establecimiento de ciertas asociaciones o conexiones del contenido, lo cual indica que es necesario considerar la experiencia dentro del acto educativo, a fin de facilitar el aprendizaje de los estudiantes, con la mediación del docente entre un discurso científico y un discurso de la realidad.

El docente considerado como el principal promotor de prácticas discursivas signadas de poder, de valores y pericias acechadas por el convencimiento “objetivo” de acciones que satisfagan sus propios intereses. Foucault a través de sus estudios permite a los docentes generar una nueva epistemología de la enseñanza, reflexionar sobre sus 
perspectivas y así ahondar en un escenario que permita el contraste de teorías con la realidad, a través de la subjetividad.

A continuación se presenta tres facetas de los estudios de Foucault donde se destaca su rol de educador:

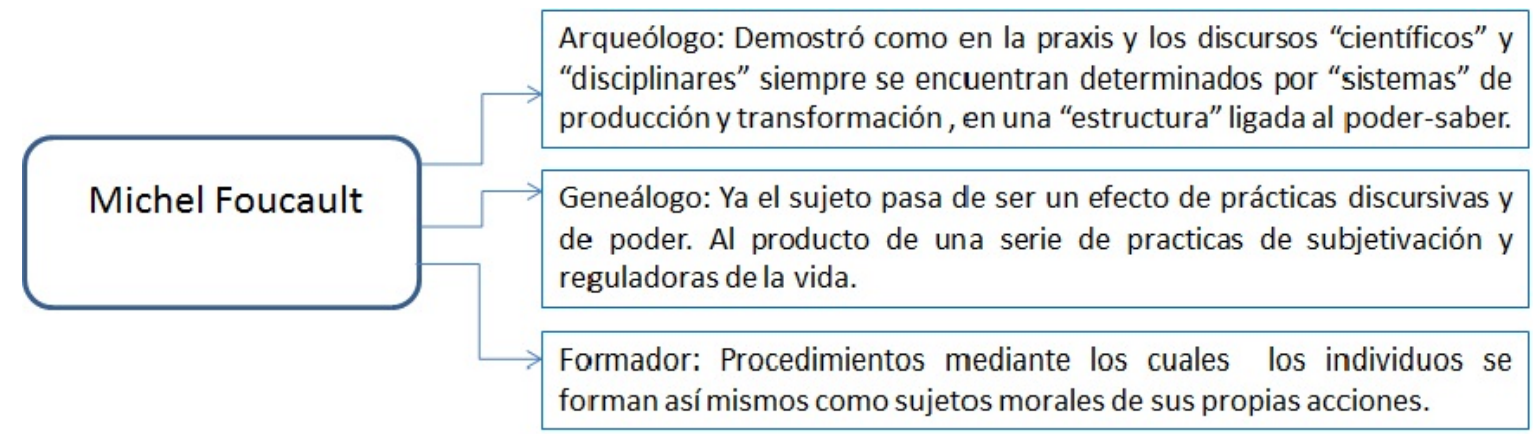

\section{Gráfico 1: Estados de Foucault. Elaborado con datos de las Obras de Foucault.}

Los estudios de Michel Foucault estuvieron signados por el trabajo arqueológico que desarrolló sobre las relaciones de poder-saber, a través de las prácticas discursivas y del poder externo ejercido sobre el sujeto, donde se pudo determinar que existe vinculación con la educación, especialmente lo expuesto a la Obra Vigilar y Castigar corresponde a la Enseñanza Tradicional . Seguidamente, con sus estudios genealógicos, estudió al sujeto como el producto de una serie de prácticas y técnicas subjetivas incorporadas en la vida, de allí que se considera esencial para la teoría que se va a construir, el ver la enseñanza con un acto de subjetividad, donde el estudiante explore dentro de sí el conocimiento.

El sentido a la moral que le da Foucault, tiene que ver esencialmente con dos problemas que han sido propios de la didáctica o de las ciencias de la educación: el problema de la formación humana y el problema de la relación que se da entre el docente y el estudiante, partiendo de aquí, se busca es la liberación del sujeto a un sistema de sujeción al que ha estado atado en el transcurrir de la historia.

\section{El Docente: Persona de reconocida moral y de comprobada idoneidad académica}

En los estudios de Foucault el poder es objeto de un cambio profundo desde las relaciones de poder y dominación, dándole mayor importancia a las prácticas y tecnologías del sí mismo, a través de un procedimiento mediante el cual los individuos se autoforman como sujetos morales de sus propias acciones. 
Aunado a esto, se puede analizar el poder como una actividad sublime que persiste asiduamente en el "sistema" considerado como el ideal para lograr la formación académica de los futuros profesionales. En consecuencia, se puede decir que existe muchas veces una veneración mágica que disfrutan los docentes, el problema inmanente de la pedagogía, radica en que suele moldear conductas a su conveniencia, no se forma en un trabajo completamente objetivo, se trata más bien de un trabajo "pedagogizado” o como un "recetario", lo que puede llevar a los estudiantes a sentirse muchas veces engañados, puesto que los docentes tienden a transmitir algo ya establecido, y ejecutan las actividades previamente planificadas sin oportunidad de cambios. Se podría decir, que el éxito como profesor universitario se obtiene gracias a la ausencia de todo cálculo respecto a la adquisición de influencia absoluta (autores, textos, ideas) ofreciendo mayor libertad a él y a sus estudiantes.

Por tanto, con la objetividad de la profesión docente, se produce desviación en su misión. Incluso en lo que afecta al docente universitario se advierte de un cambio estructural, alcanzando a convertirse el docente de forma lenta, pero muchas veces segura, en un vendedor de conocimientos. Llegando hasta a compadecerse por su incapacidad propia, para sacar de esto un mayor provecho para su propio interés.

Es importante llegar a uno de los puntos álgidos del estudio, es decir, a la función disciplinaria. Comenio (1998) no definió mal al hombre al que dijo "que era un animal disciplinable” (p.15), pues verdaderamente no puede, en modo alguno, formarse al hombre sin someterle a disciplina. El ser humano necesita del sometimiento a través de normas, reglas y pericias disciplinarias que contribuyan a su mejor desenvolvimiento en el "sistema” llevado a cabo a través de las "Instituciones”. La consideración ofrecida a la disciplina como dimensión de la investigación es el producto de la observación y entrevistas obtenidas de los estudiantes sujetos de estudio. La disciplina dada en la relación docente-estudiante, puede llegar a considerar al docente como el fuerte y al estudiante como el débil, producto de la ventaja del saber, una ventaja de la que se aprovecha ilegítimamente (el docente), puesto que es inseparable de su función, en tanto que en la realidad lo que hace es extraer de ella una autoridad de la que le resulta difícil prescindir.

Frente a esta situación puede surgir como obstáculo, lo concerniente a: si se concede a los estudiantes la oportunidad de plantear problemas, intentando así 
aproximar las clases tradicionales a la forma de seminarios abiertos, críticos, dinámicos, se obtiene poca correspondencia. Dado a que aún existen muchos estudiantes que prefieren las clases magistrales dogmáticas, ya que en ellas, el nivel de compresión suele ser inferior limitándose sólo a la memorización. Por tanto, la actitud del estudiante frente a situaciones de cambios suelen muchas veces estar viciadas por el desánimo, la apatía o el facilismo.

Una Universidad que forme los futuros pedagogos que estarán al frente del “sistema” debe hacer hincapié en el manejo de los postulados que apunten a la verdadera humanización en la enseñanza, como un valor para la vida, donde el estudiante no aprenda por cumplir con una actividad, sino porque realmente quiere saber, quiere formarse para una misión. Es importante plantearse interrogantes que ayuden a esclarecer tantas incertidumbres que surgen cuando se asume la enseñanza como profesión. En las que se pueden mencionar: ¿Cómo lograré transmitir los conocimientos a los estudiantes? ¿Las estrategias que utilizo son las adecuadas? ¿Los estudiantes estarán comprendiendo lo impartido en las clases? ¿Para qué les puede servir a los estudiantes lo que están aprendiendo en su formación?. Hay preguntas que por simples que parezcan a menudo quedan en el olvido. Puesto que la rutina, el desinterés, la desmotivación o la falta de tiempo, hacen que no nos interroguemos suficientemente acerca de ¿Por qué enseñamos?, ¿Para qué enseñamos? y ¿Cómo enseñamos?.

Como es sabido, existen docentes que se centran más en otras actividades, sobre todo en aquellas que permitan destacar su papel protagónico dentro del proceso educativo. Mediante la imposición de estrategias, recursos, materiales y evaluaciones, consideradas por él como las necesarias, suficientes e idóneas para lograr la formación integral del estudiante o para dar cumplimiento a la planificación. Existe una estructura bastante uniforme muchas veces hermética, llegando a convertirse en un patrón repetitivo en todas las clases, lo que genera apatía y descontento por parte de los estudiantes. Frente a esta situación, se considera importante las ideas de Foucault en la didáctica, para hacer que la enseñanza se convierta en la vía de la verdadera contemplación de la formación del ser humano.El estudiante: Sujeto dócil

La Educación proviene del latín Educere, que corresponde a la acepción de formación del espíritu, instrucción o llevar hacia afuera. Durante muchos años estas 
concepciones han sido objeto de múltiples estudios y enfoques, expuestos en función de diferentes puntos de vista sobre todo en el área filosófica, influenciados de gran manera por las condiciones socioculturales de cada época. Entre Los criterios dominantes de estos enfoques se encuentran los correspondientes a los aspectos sociológicos y biopsicológicos. Por tanto, la educación es concebida como parte esencial del proceso integral del ser humano. Al respecto se puede afirmar lo expresado por Kant (1961) “que si bien el hombre crea la educación, la educación crea al hombre” (p.68). El objetivo de la educación es formar al hombre para que sea una "buena” y “útil” persona en la sociedad.

De allí parte la posición de definir al ser humano como un ser biopsicosocial. Desde el punto de vista sociológico se aspira que el hombre se prepare para suplir en un momento determinado a la población adulta, quienes irán cediendo espacios para ser ocupados por nuevas generaciones. Desde el aspecto Biopsicológico, la educación tiene por objetivo llevar al hombre hasta la plenitud de su personalidad considerando para ello, todas sus potencialidades, habilidades y capacidades. La educación encuentra así, lograr sus objetivos en la sustentación de estos dos bastiones, como el proceso encargado de capacitar, adiestrar, dirigir al hombre para actuar conscientemente frente a nuevas situaciones de la vida.

Considerando lo anteriormente expresado, se puede determinar que el fin de la educación es preparar al hombre desde una visión "integral” mediante un proceso complejo de formación, mediando entre normas, disciplinas e intereses. Es decir, “moldeando conductas”. Al reflexionar sobre la concepción dada al hombre, como un ser biopsicosocial, para desarrollarse como un ser "pleno", se deja de lado los aspectos éticos y morales, esenciales en la integralidad del individuo. Si se logra abolir la concepción que se maneja con respecto a la teoría biopsicosocial cuyo objetivo radica en la formación del "Homo Faber", (hombre productivo). La educación lograría que germinase la semilla en un campo abierto, libre y productivo; obteniendo frutos de calidad, que serían frutos más naturales, puros y auténticos ${ }^{3}$.

Comenio expresa: “Cuando las escuelas formen al hombre, que le formen en la totalidad de su ser de forma que esté a la altura de las funciones que le incumban en esta

\footnotetext{
${ }^{2}$ Homo Faber: Hombre trabajador, hombre productivo.

${ }^{3}$ Metáfora para ejemplificar el acto de educar desde una perspectiva de libertad.
} 
vida y preparado para la vida eterna" ${ }^{4}$ se puede considerar a la escuela como una fábrica que convertirá a los niños en hombres. Por tanto, la escuela ${ }^{5}$ se puede considerar como una institución mediante la cual el hombre puede llegar a hallar la "verdad"; para esto, la educación tendría que estar a disposición de “todos” con la finalidad de concebir una sociedad que produzca sus propios ciudadanos.

Dentro del proceso educativo, el estudiante está inserto en un sistema de racionalidad y sometido a sus efectos que pueden llegar a ser contraproducentes o favorables, dentro de un escenario incierto; considerado como un sistema de relaciones que se puede dominar, desde una óptica instrumental (planificación, evaluación) o desde una óptica científico-técnico (conocimiento). Sujeción que debe ser desarticulada a fin de contribuir de forma significativa con la formación “plena” del Ser Humano. Así como lo expresa Peñalver (2002) la formación definida como acto para la realización de experiencias, debe estar estrechamente vinculada a las nociones de espíritu y libertad, con la oportunidad de atender la plenitud de lo humano y el cultivo de sí como experiencia ${ }^{6}$.

La educación debe estar enmarcada en la Búsqueda de la Felicidad, desde la enseñanza como un proceso natural, espontáneo, donde el estudiante exteriorice la verdad que halle en su interior. Por tanto, se puede decir que el ser humano nació para ser feliz, pero para que esa felicidad sea auténtica, debe estar sustentada en la libertad. Aspectos que deja en entredicho la "privación” de la auténtica libertad ofrecida a través de la educación, por parte de sus actores estudiantes-docentes. Aunque no necesariamente tal privativa se da solo en los estudiantes, sino también en algunos docentes que no pueden expresar abiertamente sus ideales, como producto de la imposición de líneas de acción por parte de los que dirigen las instituciones, en este caso particular la universidad. Todo ello conlleva, a una actitud de docilidad, que deja muy ajena la realidad de hallar el camino a la felicidad.

En consecuencia, la felicidad queda vetada, confirmándose lo que dice Nietzsche (2004) en su crítica del hombre moderno: “el hombre bueno es meramente corrompido y seducido por malas instituciones (tiranos y sacerdotes); la razón como autoridad; la historia como superación de errores; el futuro como progreso;... el imperio

\footnotetext{
${ }^{4}$ Comenio. Didáctica Magna Capítulo XVIII.

${ }^{5}$ En este caso la universidad.

${ }^{6}$ Peñalver, L. (2002). La formación docente en Venezuela: Compleja y Transdisciplinaria (p.11).
} 
de la justicia...la libertad” (p.76). La autorrealización del hombre, se ve afectada por factores que limitan su autonomía, su desenvolvimiento en los caminos para lograr su felicidad plena, buscando refugiarse en la educación, como la vía propicia para alcanzar sus ideales.

En este sentido, no se trata sólo de explorar desde una óptica crítica la verdad o falsedad de unas determinadas acciones propias o ajenas del sistema. Sino como lo señala Sánchez (2000) de “...desenmascarar ilusiones y autoengaños, de sospechar de aquello que se nos presente como verdadero" (p.48), en la cotidianidad del quehacer educativo. Por lo que debe existir la posibilidad de abrirse a la interpelación de todo aquello que se considera verdadero, y hallar lo más cercano a lo justo.

Es importante revisar la forma de enseñar, porque se podría caer solo en el patrón repetitivo de actividades dirigidas solo a "afinar" la "maquinaria” de producción de profesores; entre los que se puede destacar: la formación filosófica y psicológica para conocer reglas éticas y morales, adquisición de conocimientos científicos y técnicos, actividades pedagógicas, desarrollando habilidades y destrezas para ejercer la docencia. Es necesario reflexionar si se está logrando la verdadera transformación de la sociedad como objetivo pionero de la educación o solo se está convirtiendo la universidad en un patrón repetitivo. Comenio dice: "el que quiere enseñar alguna cosa a otro de noche tiene necesidad de traer luz y la espabila con frecuencia para que emita mayor claridad” (p. 77). Los docentes deben ser promotores de "luz" para sacar a los estudiantes de las tinieblas en que se encuentran envuelto ${ }^{7}$, para ello es necesario "avivar, depurar y multiplicar las luces” (p.21) y salir de la oscuridad en que muchas veces se queda envuelta la universidad producto de ser una estructura fría, rígida y hasta gris. El docente no debe quitar el sol al estudiante, para no dejarlo sumergido en el frío y la oscuridad.

\section{La escuela: sumergida en un lugar de encierro}

El trabajo de Foucault sirvió de guía para ubicar elementos “clandestinos” que suelen quedarse atados en el entramado complejo del sistema, en este caso, el educativo. Especialmente la obra Vigilar y Castigar, dio la oportunidad de construir un discurso

\footnotetext{
${ }^{7}$ Aunque este proceso puede ser interpretado de forma inversa, porque el docente puede ser el que se encuentre sumergido en la ignorancia, generando constantemente sombras.
} 
crítico y sensible de la cotidianidad hallada a través del acto educativo. Esta obra expresa claramente el nacimiento de la prisión, en el cual Foucault realiza un estudio arqueológico del paso que ocurre desde la retaliación pública de los condenados hasta el encierro mediante una estructura que es controlada y vigilada constantemente.

Se puede decir entonces que la relación saber-poder estudiada por Foucault se complementa con un tercer elemento: el espacio. Los elementos: saber, poder y espacio en la obra Vigilar y Castigar, cobran mayor fuerza. Por tanto, en la investigación se hace especial hincapié en los preceptos de las ciencias humanas, relacionados con: disciplina, control, castigo, discurso, poder y espacio. Foucault (1984) asegura que su trabajo arqueológico ha mostrado como el conocimiento desde el siglo XVII, se espacializa. Por tanto, las distribuciones espaciales son necesarias para el desarrollo del poder en la producción de conocimientos.

Al hablar de espacio, se hace necesario realizar una reflexión sobre la relación que puede existir entre una cárcel y una escuela. Puesto que, puede generar ciertos prejuicios y vejaciones; pero más allá de todo, las semejanzas relevantes que se dan al comparar una cárcel y una escuela, se debe a que son lugares de encierro y sistemas disciplinarios. La estructura ${ }^{8}$ sobria, rígida, hostil, hace de ellos lugares inertes, de sometimiento, llegando a formar sujetos “autómatas”. El tiempo considerado por el sistema educativo para lograr el paso en todos sus niveles, prolonga la estancia, por casi veinte años ${ }^{9}$, en diferentes celdas (aulas, salones, ambientes), con un saber fraccionado para lograr el avance de un nivel a otro, mediando en una estructura jerárquica dedicada especialmente al control, vigilancia y castigo.

Foucault (1980) considera que el espacio: "fue tratado como lo muerto, lo fijo, lo no dialéctico, lo inmóvil. El tiempo por lo contrario, fue rico, fecundo, vivo, dialéctico” (p.70). El espacio, tiene el efecto de exhibición, de mostrar. Por tanto, su objetivo es la posibilidad de poder ver, para tener el control y dominio, puesto que, facilita la mirada, apareciendo el tiempo, que representa: el cambio, la transformación, los avances, como producto de la transmisión del conocimiento, sujeto a un diseño curricular que posee las necesidades requeridas en el proceso de formación, propias del sistema.

\footnotetext{
${ }^{8}$ La cárcel y la escuela presentan similitud, en este caso se considera a la escuela como lugar de encierro y disciplina.

${ }_{9}^{9}$ El tiempo global que transcurre desde el pre-escolar hasta obtener un título universitario.
} 
La obra Vigilar y Castigar, articula la relación entre el poder disciplinario y la arquitectura del Panóptico ${ }^{10}$, estructura centrado especialmente en el control y en la instrumentalización del poder. A partir del espacio (estructura física), se hace uso del ejercicio del poder a través de la tecnología, permitiendo un complejo espectro de técnicas disciplinarias a través de las cuales los seres humanos (estudiantes) se convierten en “sujetos dóciles". El panóptico de Bentham, tiene un diseño arquitectónico en la que sitúa una torre en el centro de un amplio patio, y en el contorno hay un conjunto de construcciones divididas en distintos niveles (celdas), en cada celda hay dos ventanas una permite la entrada de luz y la otra va directamente a la torre, en la torre anchas ventanas permiten la vigilancia de las celdas.

Foucault (1991) expresa sobre el panóptico lo siguiente:

Basta entonces situar un vigilante en la torre central y encerrar en cada celda a un loco, un enfermo, un condenado, un obrero o un escolar. Por el efecto de la contraluz, se pueden percibir desde la torre, recortándose perfectamente sobre la luz, las pequeñas siluetas cautivas en las celdas de la periferia. (p.203)

Los sujetos que se encuentran insertos en el sistema (hospitalario, carcelario, laboral, educativo), se condicionan, es decir, buscan amoldar su conducta, debido a que están sometidos a la vigilancia constante e infinita, puesto que a través del control se garantiza el "poder” en las instituciones. Los trabajos de Foucault referidos al espacio, no sólo corresponden a una geometría formal (a la estructura), buscan analizar acontecimientos cargados de personas, problemas, resistencia, ideología, entre otros. Visto de esta manera el espacio concebido en estas instituciones simulando o no al panóptico de Bentham, buscan con su propia estructura ser "funcional” en la sociedad, donde siempre estarán sumergidas en mecanismos de disciplina, que garanticen el control y por ende el poder, sobre un grupo de sujetos dominados.

La escuela, ${ }^{11}$ presenta una estructura de encierro; el encierro entre cuatro paredes con una o dos ventanas; donde muchas veces faltan elementos que despierten el interés y motivación (como por ejemplo: los colores de las paredes, recursos didácticos),

\footnotetext{
${ }^{10}$ (diseñado en 1791) por el filósofo utilitarista de Jeremy Bentham (1748-1832).

${ }^{11}$ En este caso la universidad.
} 
influyendo de forma significativa en el proceso integral de los estudiantes. Esto sumado a la distribución física del recinto educativo: donde se tiene en algunos casos una tarima y un escritorio como el lugar del profesor, el cual permite garantizar la visibilidad y docilidad; y del otro lado los estudiantes, en los pupitres, o mesas, organizados en forma de filas, que imposibilitan, casi siempre, la interacción entre ellos mismos. El objetivo de esta geometría es lograr el control absoluto del grupo, a través de normas, reglas y condiciones impuestas por los docentes, mediante el discurso.

Por lo que, se puede decir: las sociedades generan desde su interior "espacios de encierro”. La familia, la escuela, la fábrica, el hospital, el manicomio, la cárcel, están condicionados por reglas disciplinarias. Entre los espacios de encierro, no hay posibilidades para la subjetividad plena, libre y auténtica. Por tanto, se puede decir, que “El hombre está condenado a ser libre”. Para lograr superar tal frustración es necesario hacer más comprensible, justa y solidaria las condiciones disciplinarias, a fin de contribuir de forma positiva con la plena felicidad del ser humano. En un ambiente agradable, que trascienda las cuatro paredes, donde los estudiantes tengan la oportunidad de contactar con la realidad, con el contexto que lo circunda, y así llevar los conocimientos adquiridos al servicio de la comunidad, poniendo en práctica un discurso de aliento, de renovación, de cambio, tan necesario en esta sociedad permanentemente vigilada.

\section{El discurso y sus sombras}

Lo enunciado tiene la principal intención de enfatizar que todas las prácticas sociales especialmente la aquí discutida que corresponde a la educativa, se encuentran como lo señala Lanz (1991) “intervenidas por una discursividad que no es inocente” (p.59). Siendo el discurso un recurso fundamental en la transmisión y reproducción de los conocimientos, mediante relaciones que buscan el control y dominación. Los criterios de "verdad" que operan en el proceso discursivo del acto educativo pueden llegar a ser manipulados convirtiéndose, en un instrumento de “falsedad”. Debido a que, tal como él lo señala "los impulsos cognitivos no son emanaciones "naturales” que pueden desembarazarse de los sistemas de representación imperantes por un simple automatismo del espíritu” (ob.cit.) (p.59). Las teorías educativas tradicionales, son 
abordadas de forma muy superficial dejando de lado las relaciones de poder instauradas en el interior de estos sistemas.

El poder según Lanz:

Habita preferentemente en las prácticas discursivas: como capital lingüístico, como contexto cultural, como contenido de cada discurso según su especificidad, como recorte de su realidad, como componente constitutivo de los intereses ideológicos, en fin, como singular registro de la experiencia sensorial y estética. (ob.cit.) (p.60).

Por tanto, este poder conferido mediante el discurso empleado en las relaciones sociales en este caso educativas, se consolidan aún más en el espacio físico (escuela, universidad), según ciertas competencias que se encuentran en su estado práctico por medio de las conductas.

El contexto ha condicionado la producción de los discursos en los cuales se ven envueltos en valores, pericias, ideologías, religión, entre otros, que influyen categóricamente como guía, delimitando la expansión de las prácticas cognitivas. Por tal razón, señala que "el conocimiento es siempre un resultado de compromiso entre ciertas destrezas cognoscitivas, una determinada organización de los saberes, una específica mecánica del poder” (ob.cit.) (p.60). Lo que es considerado como “verdadero” o “falso”, surge como consecuencia de la relación de fuerzas, no sólo entre los actores del proceso sino en el interior de los sistemas de representaciones que constituyen a los actores como sujetos ${ }^{12}$.

En tal sentido, el análisis del discurso requiere según Foucault hacer un estudio arqueológico, centrándose en la dimensión de exterioridad de los mismos y hallando sus condiciones de existencia en las prácticas discursivas que son, prácticas sociales. Por tanto, las prácticas discursivas producen saberes de distinto tipo que las caracterizan y delimitan sus especificidades. Foucault (1968) señala que:

...no cuestiona los discursos sobre aquello que, silenciosamente, manifiestan, sino sobre el hecho y las condiciones de su manifiesta aparición. No los cuestiono acerca de los contenidos que pueden

\footnotetext{
${ }^{12}$ Deleuze, G. Logicadu sens. (p.117).Citado por Lanz R.(1991) (p.61)
} 
encerrar sino sobre las transformaciones que han realizado. No los interrogo sobre el sentido que permanece en ellos a modo de origen perpetuo, sino sobre el terreno en el que coexisten, permanecen y desaparecen. Se trata de un análisis de los discursos en la dimensión de su exterioridad. (p.58).

Es complejo el proceso hermenéutico empleado en el discurso, llevándolo a la realidad. Existe un deseo incipiente que reaviva cualquier posibilidad de generar un discurso formidable, capaz de lograr despertar la atención y de obtener la aceptación en el contexto que se circunscribe, un deseo de encontrarse en el discurso sin tener que considerar lo maléfico, enviciado o temible que este pudiese ser. Ante este deseo, Foucault (1970) señala en su ponencia el "orden del discurso”, “que las instituciones responden de una manera irónica dado que hace que los comienzos solemnes, se rodeen de un círculo de atención y de silencio y les impone, como queriendo distinguirlos desde lejos, unas formas ritualizadas” (p.2).

Por tanto el deseo, entra en el discurso de forma decisiva, no permitiendo que se rodee como dice Foucault "de una transparencia apacible, profunda, indefinidamente abierta...en las que brotarían las verdades” (ob.cit.) (p.4). Por otra parte, se encuentran las instituciones, en la que plantea Foucault que: “el discurso está en el orden de las leyes, que desde hace mucho tiempo vela por su aparición: que se le ha preparado un lugar que le honra pero que le desarma, y que, si consigue algún poder, es de nosotros y únicamente de nosotros de quien lo obtiene” (p.3).

Se puede apreciar que el deseo y las instituciones se presentan como dos cosas opuestas con un mismo interés que es el discurso, el cual se ve condicionado y por tanto, ajeno a la realidad. Como lo indica Foucault surge también la "inquietud al sospechar la existencia de luchas, victorias, heridas, dominaciones, servidumbres, a través de tantas palabras en las que el uso, desde hace tiempo, ha reducido las asperezas”. (ob.cit.) (p.3). Todos los discursos van cargados de intencionalidad propia o por intereses de una fuerza supeditada que impone una línea de acción a fin de cumplir sus objetivos.

Por ello, es necesario que los docentes nos interroguemos aspectos como: ¿Habrá algún inconveniente si el discurso empleado en las aulas de clases es ajeno a la realidad? ¿Qué consecuencias pueden traer la proliferación por parte de los estudiantes 
de un discurso "subjetivo" ofrecido por el docente? ¿El conocimiento transmitido mediante el discurso tendrá una carga de “verdad” o falsedad”? ¿Empleamos el discurso como un medio de manipulación o de discusión? ¿Manejamos un discurso basado en el respeto individual y colectivo o en los intereses de la institución?

En el fondo lo que se está buscando es desarrollar una reflexión crítica de uno de los elementos centrales de los estudios de Foucault que es el discurso, en cuyo seno el problema del Poder está latente. Siendo necesario replantearse las formaciones discursivas para acceder a los planos de racionalidad. Tal como lo menciona Foucault que en toda "sociedad la producción del discurso está a la vez controlada, seleccionada y redistribuida por un cierto número de procedimientos que tienen por función conjurar los poderes y peligros, dominar el acontecimiento aleatorio y esquivar su pesada y temible materialidad” (ob.cit.) (p.4). El discurso nunca es neutro, por lo que podría convertirse en una herramienta discriminatoria y de exclusión, no se puede decir todo lo que se piensa, puesto que muchas veces el sistema impone y el discurso tiene que ser vetado.

El discurso, así como otros sistemas de exclusión, dice Foucault (ob. cit.) “se apoyan en un soporte institucional: a la vez reforzado y reconducido por una densa serie de prácticas como la pedagogía, el sistema de libros, la edición, las bibliotecas, las sociedades de sabios de antaño, los laboratorios actuales” (p.8). El docente como transmisor del conocimiento en el acto educativo suele apoyar su discurso que es valorizado, distribuido, repartido y en cierta forma atribuido a repeticiones adquiridas por otros docentes, a los postulados de ciertos autores, a fuentes de información propias de sus intereses, entre otras. Convirtiendo así el discurso en algo frágil, incierto, haciendo que la enseñanza sea más insoslayable de hallar la verdad.

Indagar sobre didáctica desde una perspectiva crítica que logre la reflexión, del sentir cotidiano vivido en las aulas de clases considerando las ideas de los principales representantes de la Escuela Nueva, y el lograr contrastar con las ideas de Foucault, es tratar de generar ideas enmarcadas en un pensamiento abierto, libre de cualquier obstáculo, cuyo foco central sea realzar el papel del estudiante y dar orientaciones que mejoren la práctica educativa del docente. Por ello, los autores citados como referentes teóricos son de pensamientos afines, con ideas cónsonas al sentimiento de erradicar las 
posturas tradicionalistas y explorar la docencia como un verdadero artista dispuesto a dejarse influenciar por la creatividad, motivación, libertad y respeto.

\section{CONSIDERACIONES FINALES}

- El trabajo filosófico realizado por Michel Foucault ha generado nutridas herramientas para abordar la problemática del sujeto como uno de los ejes articuladores de su pensamiento, imbuido este en relaciones de poder, por lo que a partir de sus ideas se puede contextualizar el proceso educativo universitario y ver la relación docente-estudiante como sujetos que están inmersos en un campo de poder considerado dentro del campus universitario.

- A la luz de las ideas de Foucault se puede analizar bajo un ambiente crítico, ideas que permitan entender al sujeto como un blanco de poder que está sometido a unos intereses propios de mecanismos de producción, determinados por prácticas de poder y saber, con miras a profundizar la práctica educativa universitaria buscando acciones que mejoren el desarrollo del acto pedagógico.

- Estudiar la práctica educativa teniendo como luz la obra Vigilar y Castigar de Michel Foucault, puede servir para analizar el contexto educativo llevado a cabo en cualquier universidad. Hoy día los actores que deciden y planifican las diversas orientaciones educativas, no toman en cuenta las vinculaciones existentes con la realidad personal y social. De allí la pertinencia de continuar con estos estudios, pues se aspira, no sólo lograr el conocimiento desde el punto de vista académico, sino también la búsqueda, a través de diversos enfoques teóricos, de una didáctica universitaria que sea integral.

\section{BIBLIOGRAFÍA}

BALL, S. (1990). Foucault y Educación: Disciplina y Saber. London: Routledge

COMENIO, A. (1998). Didáctica Magna. (Obra original Publicada en 1630).

México: Edit Porrúa. Disponible http://www.pedrogoyena.edu.ar/Didactica_Magna.pdf

FILLINGHAM, L. (2006). Foucault para Principiantes. Buenos Aires: Edit. Era Naciente. 
FOUCAULT, M. (1968) “La función política del intelectual. Respuesta a una cuestión” en Saber y Verdad. Madrid: Ediciones de La Piqueta.

FOUCAULT, M. (1970). El Orden del Discurso. Buenos Aires: Tusquets

FOUCAULT, M. (1980). Vigilar y Castigar: nacimiento de la prisión (Aurelio Garzón del Camino, Trad.). España: Edit. Siglo XXI.

FOUCAULT, M. (1982). Hermenéutica del Sujeto. Madrid: Akal, S.A.

FOUCAULT, M. (1994) Nietzsche, la genealogía, la historia en Microfísica del Poder. Buenos aires: Planeta-Agostini.

FOUCAULT, M. (2002). La Arqueología del Saber. Buenos Aires: Siglo XXI editores.

FOUCAULT, M. (2007). Sexualidad y Poder. Barcelona: Ediciones Folio S.A.

FOUCAUlT, M. (2008). El Nacimiento de la Clínica. Argentina: Artes Gráficas del Sur.

MORÍN, E. (1996). Introducción al Pensamiento Complejo. Madrid: Gedisa.

NIETZSCHE, F. (2004). El Caminante y su sombra. Madrid- España: Editorial EDIMAT Libros.

NIETZSCHE, F. (2004b). La Voluntad de Poder. Madrid- España: Editorial Edad (Obra original publicada 1888). 12º Edición.

NIETZSCHE, F. (2006). La Genealogía dela Moral. Madrid- España: Editorial Closas-Orcoyen.

PEÑALVER, L. (2002). Artículo “Hacia una Historia de la Formación Docente en Venezuela” Venezuela: UPEL-IPM.

SAVATER, F. (1997) El Valor de Educar. Barcelona. Editorial Ariel.

TIRADO, F. (2002). El espacio y el poder: Michel Foucault y la crítica de la historia. España: Universidad Autónoma de Barcelona. 